\title{
Carnets
}

Revue électronique d'études françaises de l'APEF

Deuxième série - 15 | 2019

Jules Verne et les pouvoirs de l'imagination

\section{Representações do homem de ciência nas Viagens extraordinárias}

Paulo Lavoura

\section{(2) OpenEdition}

Journals

Edição electrónica

URL: http://journals.openedition.org/carnets/9273

DOI: 10.4000/carnets.9273

ISSN: 1646-7698

Editora

APEF

Refêrencia eletrónica

Paulo Lavoura, "Representações do homem de ciência nas Viagens extraordinárias », Carnets [Online], Deuxième série - 15 | 2019, posto online no dia 31 janeiro 2019, consultado o 24 abril 2019. URL : http://journals.openedition.org/carnets/9273; DOI : 10.4000/carnets.9273

Este documento foi criado de forma automática no dia 24 Abril 2019.

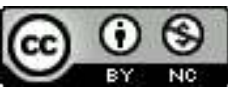

Carnets est mis à disposition selon les termes de la licence Creative Commons - Atribution - Pas d'utilisation commerciale 4.0 International. 


\title{
Representações do homem de ciência nas Viagens extraordinárias
}

\author{
Paulo Lavoura
}

\section{NOTA DO AUTOR}

Este trabalho insere-se no projeto de investigação para a dissertação « A obra de Jules Verne e alguns aspetos da sua receção em Portugal (1863-1922) », do curso de Doutoramento em Estudos Contemporâneos (CEIS20-III, Universidade de Coimbra), cujos orientadores são os Profs. Doutores Ana Leonor Pereira e João Rui Pita.

\section{0 cientista como Benfeitor da Humanidade ou a matriz prometaica do homem de ciência}

1 Depois do Iluminismo, na diversidade do panteão ideológico e cultural da modernidade, o cientista, ao lado do poeta, do artista e do pensador, ocupa um lugar de singular proeminência. Rica de significações ideológicas e de potencialidades dramáticas, associada ao advento da ciência, em particular, à ascensão das ciências naturais (físicas e biológicas) ao estatuto de formas superiores do saber humano, anteriormente reservado à Filosofia e à Matemática, a figura do sábio cientista marca presença significativa em todas as formas de expressão artística, tanto na literatura como nas artes, e impõe-se como uma das mais paradigmáticas formas de representação da História das ideias e das mentalidades do século XIX.

2 Contrariamente ao artista romântico que rompia com as normas estabelecidas refugiando-se numa marginalidade provocatória, o cientista sábio do século xIX é um indivíduo típico do seu tempo, não só se identificou com o saber científico da sua época como também assumiu os valores que permitiram a edificação da sociedade burguesa. Modelo de probidade e de seriedade, no campo intelectual mas também moral, o sábio cientista ilustra a síntese perfeita dos valores e das virtudes que enformam a 
mundividência burguesa. A primeira das virtudes desta mentalidade assimiladas pela representação da figura do cientista na literatura é a virtude do trabalho. 0 homem de ciência, seja de campo, de gabinete ou de laboratório, é acima de tudo um homem de trabalho. A esta encarnação do espírito de labuta incessante, o sábio cientista do século XIX, soma outras virtudes fundadoras da sociedade burguesa, nomeadamente, a audácia, a tenacidade, a perseverança, a sagacidade, a prudência e a economia. São muito poucas as personagens principais da ficção verneana que não são movidas por uma grande audácia e espírito empreendedor os quais, por sua vez, estão alavancados numa profunda confiança nas capacidades auto-realizadoras do indivíduo. Por outro lado, enquanto o artista romântico é um ser instável, disperso e dado ao desperdício, o cientista apresenta uma conceção economicista da existência, procedendo por retenção e por acumulação. Desta forma, a soma dos seus conhecimentos científicos resultará, lentamente, por entesouramento, na acumulação de uma fortuna, um património que não é feito de factos isolados mas da totalidade de um saber durável que ele todos os dias com o seu trabalho mais do que conservar faz frutificar. Curiosamente, os comportamentos subjacentes a esta prática, não estão relacionados com uma qualquer perspetiva egoísta. Pelo contrário, o capital de conhecimento acumulado pelo sábio cientista graças ao seu trabalho árduo, à maneira de Pasteur considerado um verdadeiro Benfeitor da Humanidade, passa a ser património de todos e é colocado ao serviço da comunidade. Desta tipificação do sábio positivista filho de uma ciência republicana e democrática, materializada nas obras de Flaubert, Vítor Hugo, Zola e reforçada pelo permanente elogio do trabalho e da economia resultou uma conceção profundamente otimista da ciência e dos cientistas como homens superiores, serenos e modestos porque estão somente preocupados com a verdade e com a ciência, distintos pelo saber e pela inteligência, socialmente reconhecidos e honrados pelos poderes públicos mas sem ambição pessoal. Características que assentam como uma luva à primeira das personagens que trazemos a esta galeria, o médico britânico, Dr. Clawbonny, das Viagens e Aventuras do Capitão Hatteras (1864-65). Membro da sociedade literária e filosófica de Liverpool e grande entusiasta das ciências físicas e naturais, sempre disposto a partilhar os benefícios da sua ciência com a tripulação do Forward e dotado de um otimismo inquebrantável mesmo nas situações mais críticas. A esta adorável e modesta figura anafada, as Viagens Extraordinárias e o seu omnipresente sentido pedagógico devem um dos mais eloquentes libelos a favor da educação e do conhecimento. Muito justamente, poderia ser utilizada como uma das passagens mais emblemáticas de toda a coleção :

Estou a dizer-lhe que não sei nada, que a única coisa que sei é que sou um ignorante. Ora, oferecem-me a possibilidade de completar, ou, para me expressar melhor, de readquirir os meus conhecimentos de medicina, de cirurgia, de história, de geografia, de botânica, de mineralogia, de conquiliologia, de geodesia, de química, de física, de mecânica, de hidrografia ; pois muito bem, eu aceito, e garanto-lhe que não é preciso insistir!

- Nesse caso - retorquiu Shandon, desapontado -, o senhor não sabe para onde se dirige o Forward?

- Sim, sei comandante ; o navio vai aos lugares onde há coisas para aprender, para descobrir, que nos instruam, que possamos comparar, e em que haja outros costumes, outros países, outros povos a estudar no exercício das suas funções ; para resumir, este navio dirige-se para um lugar onde eu nunca estive. (Verne, [s.d.] : 30).

Por outro lado, o conhecimento científico, para além desta faceta desinteressada do saber pelo saber, também dá aos seus detentores uma inquestionável sensação de poder. Para o cientista que se superioriza aos seus semelhantes e que faculta os meios técnicos 
aplicáveis ao mundo real capazes de o transformar, saber só pode significar poder. É nas suas mãos que são colocados os misteriosos poderes que a ciência confere aqueles que sabem como descobrir alguns dos seus segredos. Porque a ciência trabalha sempre sobre os limites e os seus progressos concretizam-se sobre o território do Desconhecido, o cientista, possuidor de um conhecimento superior e de uma técnica cujos meios lhe permitem tudo alcançar, altera a ordem do mundo estabelecida por Deus e, inevitavelmente, converte-se num transgressor. Neste sentido, todo o cientista pode reclamar para si o perturbante estatuto de super-homem. Como não ver nesta situação singular um problema filosófico de grande complexidade, que não poderia deixar de interessar à literatura de um homem que foi espelho do seu tempo, sobre o uso que faz o cientista do incomensurável poder que tem ? No quadro mitológico dos atributos sobrehumanos, duas formas distintas de exercer um poder desmesurado saídas de um ato de rebeldia e de revolta, encaixam perfeitamente nos dilemas intrínsecos ao homem de ciência de qualquer tempo: o mito de Prometeu e o mito de Satanás. O primeiro, desenvolvido no âmbito da civilização greco-romana, explana os poderes sobrenaturais de Prometeu como os de alguém que se assume como benfeitor da Humanidade. Prometeu, por amor aos homens, protagoniza uma revolta desinteressada, a sua punição executada com requintes de crueldade foi uma tremenda injustiça. O segundo, produzido pela mitologia judaico-cristã, encarna a sublevação movida pelo orgulho solitário de um sedutor egoísta orientada para a escolha deliberada do mal e da destruição. $O$ seu castigo e o daqueles que arrasta consigo para a perdição são a paga justa para os seus crimes. Os homens de ciência da literatura verneana e da literatura do século XIX por serem figuras potencialmente dotadas de poderes sobre-humanos que podem ser direcionados para o Bem, mas igualmente para o Mal, encarnam nas suas características, atitudes e comportamentos, os aspetos fundamentais destes dois mitos fundadores da civilização ocidental.

4 A ciência, para Jules Verne, não deverá ser um fim em si próprio mas sim um auxiliar para praticar o bem. Por conseguinte, no que concerne às personagens das Viagens Extraordinárias que se filiam na matriz prometaica, para além de serem fortemente inspiradas nas biografias de homens de ciência célebres como Pasteur, principal figura da ciência do século XIX, mas também Cuvier, Fourier, Biot, Magendie, Charcot, Claude Bernard, Bertrand, Marcelin Berthelot, também revelam a propensão algo paradoxal de não se assumirem como cientistas de profissão, mas sim homens de ação e de forte dimensão prática, que se misturam de maneira perfeitamente harmoniosa com esse espírito empreendedor tão característico da mentalidade burguesa da segunda metade do século XIx. A este propósito, não deverá surpreender que o escritor patenteie uma afeição particular pelos engenheiros, cientistas de ação, se assim lhe pudermos chamar. $\mathrm{Na}$ realidade, com graus de protagonismo diverso, alguns figurantes, outros verdadeiros protagonistas, esta atividade, que dezasseis personagens podem reclamar, afirma-se como uma das mais relevantes das Viagens Extraordinárias:

Para Júlio Verne o verdadeiro cientista não é o homem de gabinete debruçado sobre os seus livros, nem o mineralogista ou o naturalista fechados na sua especialidade sem se interessarem por nada nem por ninguém. Nem tão pouco o inventor, genial talvez, mas obcecado pela sua invenção ao ponto de vender a sua alma ao diabo para a realizar ; [...] o verdadeiro cientista é o homem que, dispondo dos recursos da ciência, os mete ao serviço da Humanidade para tentar melhorar a sorte dos seus semelhantes (Diesbach, $2000: 177$ ). 
O engenheiro Cyrus Smith, de A Ilha Misteriosa (1874-75), que com a sua sabedoria e a boa vontade dos seus companheiros fez de uma ilha deserta um « albergue das maravilhas da civilização », o engenheiro-rei de toda a coleção, impõe-se como cientista modelo no que diz respeito à explicitação da componente prática e abnegada do ofício, verdadeiramente, o engenheiro-tese, se assim lhe pudermos chamar, das personagens que colocam ao serviço da Humanidade os talentos da sua ciência :

Cyrus Smith, originário do Massachussets, era um engenheiro, um sábio de primeira ordem, ao qual o governo da União confiara, durante a guerra, a direcção dos caminhos-de-ferro, cujo papel estratégico foi tão considerável. [...]. Muito instruído, muito prático, "muito desenrascado", para empregar uma palavra da língua militar francesa, era um temperamento soberbo, porque, ficando senhor de si, quaisquer que fossem as circunstâncias, preenchia no mais alto grau estas três condições cujo conjunto determina a energia humana: actividade de espírito e de corpo, impetuosidade dos desejos, poder da vontade. E a sua divisa teria podido ser a de Guilherme de Orange no século XVII : "Não preciso de esperar para empreender, nem de triunfar para perseverar” (Verne, 1991 : 14-15).

6 Sob a dedicada direção de Cyrus Smith, simultaneamente homem de ação e de pensamento, que associa qualidades intelectuais superiores a uma extraordinária capacidade física, cinco náufragos do ar vão, numa ilha que faz lembrar o princípio do mundo, reinventar a agricultura e a indústria. Durante dois anos, os cinco sobreviventes, sem qualquer instrumento ou ferramenta, dispondo unicamente de um fósforo, de um grão de trigo e de dois vidros de mostradores de relógios, os únicos bens salvos do naufrágio, vão lançar-se na ciclópica empresa de reconstituir, mais do que simplesmente a sociedade industrial que tinham abandonado, muitos milénios de evolução científica e tecnológica da própria humanidade. Com um inesgotável espírito inventivo feito de energia, inteligência, zelo e dedicação, os colonos vão conseguir maravilhas dignas dos espíritos mais prodigiosos.

\section{O savant ridicule e a representação do cientista como um ser original}

7 Na produção literária do século xIX, a este modelo certamente idealizado da figura do cientista como um grande homem, há que acrescentar uma representação bastante mais ambígua que aproxima o sábio moderno de figuras cómicas e grotescas na linha dos feiticeiros e alquimistas da Idade Média ou, para não irmos tão longe, na tradição da forma como os médicos eram representados na obra dramática de Molière. Correspondendo a uma das perspetivas românticas de ver a figura do cientista, que revela o paradoxo da atitude burguesa perante a ciência e os cientistas, adicionando à incensada reverência com que estes eram tratados uma desconfiada zombeteria, esta representação do savant ridicule, particularmente vívida em muitos livros de Jules Verne, está relacionada com o desejo popular e ancestral de troçar daquilo que não é imediatamente compreensível ou útil e, sobretudo, com a vontade de contestar uma superioridade fundada em critérios intelectuais impalpáveis que não estão por isso subjacentes a realidades materiais tão ao gosto do imaginário burguês, como o dinheiro, os bens, o poder conferido pelos cargos ou a aparência física :

O exemplo de Júlio Verne é a este respeito bastante impressionante. A sua obra, que se apresenta aparentemente como um elogio permanente da ciência e das suas aplicações técnicas, é sem dúvida uma das mais ricas em figuras de sábios ridículos. [...]. Estas personagens são sábios perfeitamente estimáveis, cientistas 
irrepreensíveis e até mesmo superiores aos seus contemporâneos e, ao mesmo

tempo, marionetas ridículas (Noiray, 1998 : 149).

Convocando traços de burlesco para o aspeto físico e para a dimensão moral das personagens, uma caracterização recorrente e caricatural que Jules Verne faz do homem de ciência é a de um homem magro, sempre com os mesmos óculos que ampliam o seu isolamento do mundo exterior, com um grande crânio de intelectual consumido por uma ideia fixa e com um comportamento marcado por dois traços dominantes que tem origem numa inadaptação ao mundo real e que produzem um grande efeito cómico, a distração e a cólera. Por outro lado, corporizando a ideia preconcebida que o grande público tem dos sábios exclusivamente mergulhados nos mistérios das ciências puras, sejam elas as matemáticas, a física ou a astronomia, o cientista é frequentemente apresentado como um ser "original". Esta originalidade é bizarra e de traços bastante carregados, afinal de contas aquela frase popular que diz que "só te ris do mal" não é destituída de sentido, as qualidades só têm graça se forem a tal ponto excessivas que se transformam em defeitos. As qualidades/defeitos desse ser "original" que dá pelo nome de Paganel, de Os Filhos do Capitão Grant (1868), na circunstância a sua lendária distração, a cólera de Palmyrin Rosette, esse «original absolutamente incorrigível» de Heitor Servadac (1877), ou a do professor Lidenbrock, esse "terrível original» da Viagem ao Centro da Terra (1864), constituindo-se como elementos cómicos que um romancista não poderia deixar de explorar e motor eficaz da ação dramática, divertem o leitor e, ao mesmo tempo, vão-lhe chamando a atenção, não obstante a sua feição inofensiva, no fundo quase todos estes seres exóticos tem um bom coração, para os riscos de uma ciência potencialmente perigosa. Lamentavelmente, por manifesta falta de espaço, só os dois primeiros espécimenes poderão ser alvo nestas linhas de uma análise mais detalhada. Realizemo-la sem demora.

9 Jacques Paganel, secretário da Sociedade de Geografia de Paris, possui memória prodigiosa e erudição geográfica monumental : « um dos sábios mais distintos da França » (Verne, 1989: 50). Goza de uma elevada reputação internacional. Figura inofensiva e despreocupada, exótica, bizarra e desajeitada : « Aquele homem alto, seco e magro, podia ter quarenta anos, assemelhava-se a um prego comprido com uma grande cabeça (Verne, 1989 : 45). Espírito vivo e em permanente ebulição, possuidor de um carácter alegre e descontraído de colegial em férias a roçar a inconsciência. Trato amável e aparência jovial, mesmo nas situações mais inusitadas e perigosas. E finalmente, o traço mais carregado, a sua lendária, incrível e fenomenal distração : acreditando encontrar-se a bordo do Scotia numa rota para a Índias, constatou que afinal tinha entrado no Duncan cujo destino se situava no outro lado do mundo.

10 A cólera de Palmyrin Rosette : «Palmyrin - informava o capitão Heitor - é um original absolutamente incorrigível, teimoso até ao extremo de cabeçudo, colérico até às raias do possesso, impertinente e rabugento ao último ponto, mas, no fim de tudo, homem de bem e científico e valer » (Verne [1971] : 17). Antigo professor de Física no Liceu Carlos Magno, Palmyrin Rosette, sábio incompreendido, tinha decidido abandonar o ensino a fim de se consagrar exclusivamente à astronomia. Tendo sido o responsável pela descoberta de três novos planetas e uma vez que foi excluído pelo governo francês da expedição oficial para comprovar a medida do Arco Terrestre já calculada por Arago, dada a sua profunda vaidade, feitio caprichoso e incapacidade de trabalhar em grupo, resolveu fixar-se às suas expensas na ilha Balear de Formentera para sozinho se dedicar a esta missão. Seria deste posto de observação que o cientista viria a avistar um cometa a aproximar-se 
perigosamente da Terra e também, como a personagem que dá nome ao livro, a ser engolido por este. Contrariamente aos outros habitantes, Rosette vive para o seu cometa e não se importa nada que ele o transporte para longe da sua terra e para longe do globo terrestre, conquanto esta catástrofe cósmica permita verificar os seus cálculos e confirmar as suas teorias por forma a ver o seu nome associado à maior descoberta científica do século. Na verdade, com mais frequência do que costumam confessar, os sábios são consumidos pela vaidade, pelo desejo de reconhecimento e de prestígio, pela procura dessa suprema glória que é a de deixarem o seu legado para a posteridade. Perseguindo sonhos de celebridade, Rosette vive literalmente desligado da humanidade, exclusivamente para o seu trabalho. Por conseguinte, da parte de Jules Verne, a forma obsessiva como este cientista encara a sua profissão, vale-lhe, como valeu a outras tantas personagens de outras áreas científicas que tem a mesma atitude fechada da ciência pela ciência, um retrato caricatural típico do savant fou, egocêntrico, misantropo, irascível, teimoso, temperamental, mas, no final, inofensivo.

\section{Os cientistas loucos e a dimensão satânica do homem de ciência : a loucura como punição suprema}

11 Partindo do princípio que a Ciência pode ser considerada, sem exagero, a grande religião do século XIX e a obra de Jules Verne um dos seus mais eloquentes evangelhos, não deixa de ser curiosa a forma como o escritor ao mesmo tempo que acolheu com uma fé quase mística as suas últimas revelações as faz acompanhar de um pessimismo e de uma tragicidade particularmente incisiva no que respeita ao uso que alguns dos seus protagonistas fazem dos seus conhecimentos científicos. Vistas bem as coisas, não poderia ser de outra forma. A grande ambiguidade da representação literária da figura do cientista não se poderia esgotar na representação modelar do cientista como um Benfeitor da Humanidade ou na excentricidade benigna do cientista ridículo e original. Uma outra bizarria mais sombria e bem mais ameaçadora, reflexo de um outro posicionamento romântico e anti-positivista sobre os homens de ciência, personificada na figura do savant fou, do cientista louco, teve igualmente um grande destaque na produção romanesca do nosso autor, em particular, e um pouco por toda a literatura tardo oitocentista. Com efeito, com uma frequência assaz reveladora, a figura do sábio/cientista/inventor, quando não associa ao exercício da sua atividade um vincado sentido ético que procure melhorar a vida dos seus semelhantes colocando ao serviço da Humanidade os recursos da sua ciência, é representada como um ser delirante, maníaco e alucinado, frequentemente mais perigoso do que útil, cujas falhas, existência solitária, orgulho descomunal, planos megalómanos, ambições e atitudes ridiculamente desmesuradas metaforizam com um sentido profético as grandes catástrofes do século Xx desencadeadas por posicionamentos éticos irresponsáveis e por uma utilização errónea das aplicações científicas.

Está chegado o momento de abordarmos o reverso satânico na medalha da representação da figura do cientista. Tudo começa na solidão misteriosa do ato de investigação científica. A superioridade do cientista que o eleva ao estatuto de super-homem também o separa e isola do resto da humanidade. Porém, este isolamento necessário para o cientista fazer o seu trabalho e para se destacar do resto dos mortais, pode ser um privilégio perigoso. Separado dos seus semelhantes e dos cuidados que estes lhe podem proporcionar, o cientista depara-se sozinho com a possibilidade de ceder à tentação do orgulho e do poder egoísta. É nesta solidão que o cientista pode prescindir do estatuto de 
Prometeu e vender a sua alma ao diabo sucumbindo ao aspeto tentador de uma ciência prometedora de glória, de prestígio e de poderes sobrenaturais. É neste ato de transgressão, nesta vaidade pela violação de uma lei divina, que se vai consubstanciar a imagem satânica do homem de ciência. Não a transgressão, benigna, também ela ousada e desafiadora de Prometeu realizada por amor aos homens, mas na insubordinação resultado de uma revolta egoísta, impaciente e orgulhosa. Por conseguinte, para aqueles que movidos unicamente pelo orgulho veem a ciência apenas como um fim em si mesmo e um meio para a realização de vontades individuais, por muito inabaláveis que elas sejam, Júlio Verne assume a posição daquele crente que por tanto venerar a sua religião - a Ciência, está disposto a ser militantemente anti-clerical em relação a alguns dos seus sumo-sacerdotes. $O$ seu alvo, em concreto, são aqueles que se dedicam em exclusivo ao culto da ciência pela ciência e não procuram o bem-estar do seu próximo. Por este motivo, sublinhe-se uma vez mais, para os que negligenciam a função social da ciência e menosprezam os seus deveres de comunhão com o Outro e com a Humanidade, para os que renegam as suas obrigações de modéstia, de abnegação e de fraternidade, está-lhes sempre reservado um destino trágico e fatídico, certamente a morte, mas sobretudo a loucura, um estado para o qual o cientista sábio está à partida tão inclinado, a sanção única e necessária, a catástrofe apropriada para aqueles que trabalhando nos limites do cognoscível numa situação de grande poder são culpados dos crimes de desordem e de orgulho desmesurado.

13 Tal é o caso de Thomas Roch, o inventor rejeitado de Em Frente da Bandeira (1896). Na vasta galeria de cientistas loucos presentes nas Viagens Extraordinárias, escolhemos para inaugurar a nossa reflexão sobre este tipo específico de sábio, a figura amargurada e vingativa deste genial cientista francês porque, ao que tudo indica, ela foi inspirada na vida do químico, efetivamente caído em desgraça, Eugène Turpin (1848-1927). Como Roch, podemos enumerar outras personagens passíveis de serem incluídas no grupo heterogéneo dos sábios e cientistas loucos ou com fortes perturbações mentais, tais como : Herr Schultzeid, o odioso cientista de os Quinhentos Milhões da Bégum (1879), Marcel Camaret, o prodigioso engenheiro de Blackland de A Espantosa Aventura da Missão Barsac (1914), o engenheiro Robur, esse Ícaro dos tempos modernos de Robur o Conquistador (1885), o Mestre Zacharius (1854), mestre relojoeiro e inventor atormentado, a sombria e taciturna personagem que melhor representa a metáfora alquímica que apresenta o homem de ciência como uma espécie de mágico e que é alimentado por um orgulho monomaníaco que o haverá de conduzir à perdição, o capitão Hatteras, o intrépido explorador do Ártico que sacrificou uma expedição inteira para perseguir o sonho inquebrantável de ser o primeiro homem a pisar o Pólo Norte em Viagens e Aventuras do Capitão Hatteras, ou do próprio capitão Nemo de Vinte Mil Léguas Submarinas (1870), em rutura absoluta com os deuses em atitude de sublime e romântico desafio.

14 É bem verdade que o contraste entre o posicionamento prometaico e a postura satânica no homem de ciência aparece muito bem explicitado no romance Os 500 milhões da Bégum. Neste o doutor Sarrasin, francês que consagra o seu talento científico e parte da sua herança dos 500 milhões da Begum à edificação de France-Ville, uma cidade modelo que possa proporcionar a melhor qualidade de vida e o máximo de conforto aos seus habitantes mais desfavorecidos, representa a figura de tese prometaica. Herr Shultze, primo de Sarrasin, alemão, professor de Química na Universidade de Iena, dotado de grande inteligência e de grande orgulho nela, desagradável, egoísta e tirânico, nazi avant la lettre pela sua xenofobia que preconiza o extermínio de todos os povos que recusem 
fundir-se com o povo alemão, utiliza a fortuna e inteligência científica para dar livre curso ao seu génio construindo a sinistra Stahlstadt, fábrica de armamento e de canhões que haverão de estar apontados à cidade do seu primo, simbolizando o formidável poder de destruição que a Ciência pode proporcionar a alguém exclusivamente orientado para o Mal. Não obstante, decidimos dar destaque nestas páginas a Marcel Camaret de $A$ Espantosa Aventura da Missão Barsac. Trata-se de uma figura ambivalente, homem de génio dotado de capacidades intelectuais excecionais e, ao mesmo tempo, afetado por uma grande ingenuidade e por uma vulnerabilidade infantil que o faz ser capaz das atitudes mais gravemente insensatas, nomeadamente a de ter o atrevimento megalómano de se comparar a Deus :

Então quem será o autor ?, perguntou Barsac.

- Eu !..., pronunciou altivamente Marcel Camaret, com o rosto a rebrilhar de orgulho. Fui eu que criei tudo o que aqui existe. Fui eu que espalhei a chuva benfazeja sobre o solo árido e crestado do deserto. Fui eu que o transformei em campo verdejante e fértil. Fui eu que do nada fiz esta cidade, como Deus do nada fez o Universo! (Verne, $1978: 28-29$ ).

A mania das grandezas é apanágio dos sábios inflamados por um orgulho desmesurado. $\mathrm{Na}$ ambição irreprimível, na transgressão audaciosa do território interdito que é o ato de criação divina, no pacto com as forças do Mal que tornam todos estes sonhos possíveis, no destino fatal que só pode ser a justa paga para quem cometeu o supremo sacrilégio, Camaret converte-se num digno embaixador da plêiade de personagens que, consciente ou inconscientemente, direcionam os seus esforços e manuseiam os instrumentos da ciência para a satisfação de um objetivo pessoal, sem terem a noção de que o resultado do seu trabalho científico, se exercido de forma irresponsável, pode ter consequências catastróficas. Ainda que no final do romance, apareça a redenção, mas também a condenação inevitável, a sua sinistra criação, Blackland, é o resultado de uma mente perturbada e egocêntrica cheia de contradições, cientificamente genial é certo, mas de alguém completamente alheio a tudo que constitui a vida material e a quem nunca ocorreu, de tal modo estava mergulhada na componente abstrata da sua criação científica, interrogar-se sobre a aplicação prática dos seus inventos. Foi por este motivo, por esta personagem-tipo sublinhar de uma forma significativamente vincada e realista as responsabilidades do cientista que nunca deverá descurar os efeitos práticos das suas descobertas no mundo exterior, por muito geniais que elas sejam, e a este respeito vemnos imediatamente à memória o remorso que Albert Einstein sentiu até ao fim dos seus dias pelas possibilidades que o seu trabalho científico abriu à criação da bomba atómica, que decidimos com ela encerrar esta reflexão sobre os cientistas loucos na obra de Jules Verne.

\section{As exigências do cientista explorador}

16 A transmissão de informação sobre a descoberta e a exploração da Terra foi um dos eixos centrais das Viagens Extraordinárias e uma das grandes paixões de Júlio Verne, ele mesmo um viajante inveterado. 0 próprio título, Viagens Extraordinárias por Mundos Conhecidos $e$ Desconhecidos, outorgado pelo editor Hetzel, constitui um revelador programa a respeito da importância concedida aos exploradores e aos viajantes, não devendo, por conseguinte, surpreender, que a maior parte dos heróis dos seus romances de aventura se dediquem a esta atividade : 
Exploram a Terra até aos países mais remotos e às regiões mais hostis ; navegam pelos oceanos e atravessam os continentes enfrentando todos os perigos; alguns enterram-se nas profundezas subterrâneas ou submarinas, em busca do desconhecido ; outros elevam-se na atmosfera, como valorosos conquistadores dos ares. (Cotardière, $2005:$ 75).

17 Este espírito de curiosidade e de conquista, este autêntico fervor, este irreprimível desejo dos homens de descobrir a terra incógnita, esta poderosa e deslumbrada atração por territórios desconhecidos corresponde, nos romances de Jules Verne, a uma verdadeira pulsão do género humano. Mantendo-se fiel à matriz eminentemente pedagógica de divulgador científico, Jules Verne não só consagrou a este tema uma monumental Histoire des grands voyages et des grands voyageurs, cujo terceiro volume foi dado à estampa em 1880, como também, ao longo de toda a coletânea, sempre que a oportunidade o permitia, não cessou de enumerar abundantemente os nomes e os feitos de exploradores de todas as épocas e de todas as nacionalidades. Esta faceta é claramente visível logo no primeiro dos romances da coleção, Cinco Semanas em Balão, quando são homenageados os cento e vinte e oito (!) viajantes que se destacaram na exploração do continente africano.

Numa obra toda ela consagrada à glorificação da viagem, enquanto os exploradores "verdadeiros" são citados de forma copiosa, as personagens verneanas que realmente exerceram esta atividade contam-se pois, sublinhamos uma vez mais, entre os mais memoráveis protagonistas de toda a coleção. Destacam-se, como ilustres representantes deste grupo, Samuel Ferguson de Cinco Semanas em Balão (1863), o eclético e compulsivo explorador que decide lançar-se na descoberta e reconhecimento do continente africano depois de já ter feito o mesmo na Austrália, na América, na Índia e no Tibete. 0 sedentário professor Liddenbrock, um explorador atípico que empreende a sua Viagem ao Centro da Terra unicamente com o intuito de verificar as asserções enigmáticas de um alquimista do século XVI. $O$ capitão de longo curso Erik Hersebom que para cumprir uma missão ao serviço do governo sueco para resgatar o explorador NordensKjold intenta uma viagem circumpolar em $O$ Náufrago do Cynthia (1885). Os três audaciosos ocupantes do óbus Columbiad de Da Terra à Lua (1865) e de À Volta da Lua (1869) - Impey Barbicane, o capitão Nicholl, Michel Ardan, e ainda o capitão Servadac de Heitor Servadac (1877), protagonistas dos romances que constituem verdadeiros tratados de astronomia popular, podem certamente contar-se no rol dos exploradores, na circunstância, de uma estirpe verdadeiramente especial, assim como o capitão Nemo de Vinte Mil Léguas Submarinas, uma vez que se lançam na conquista da lua, do espaço extraterrestre, do sistema solar e das profundezas submarinas. Por último, mas não menos importante, John Hatteras, a misteriosa, intrépida e excêntrica personagem das Viagens e Aventuras do Capitão Hatteras, o famoso romance polar de Jules Verne com o qual o escritor vai imortalizar o género do romance de aventuras, sob a forma particular da novela de exploração geográfica, através da invocação épica, fascinante e poética dos perigos, da beleza e dos encantos das viagens polares. O interesse do romancista pelo Ártico foi certamente alimentado pelo mito, muito discutido pelas sociedades de Geografia na segunda metade do século XIX, da existência de um mar livre de gelo junto ao Pólo e pela realização de várias expedições que procuravam uma rota marítima que unisse o Atlântico ao Pacífico pelo norte da Rússia, a Passagem do Nordeste, aberta através do estreito de Bering em 1878-1879, ou pela Passagem do Noroeste, através do arquipélago ártico canadiano, aberta entre $1903 \mathrm{e}$ 1906.

19 A 2 de Agosto de 1859, o capitão do Forward, que assina com as enigmáticas iniciais $K$. C., endereça uma misteriosa carta ao futuro imediato do navio Richard Shandon a requisitar 
os seus serviços, contra o pagamento de uma generosa quantia, para uma missão ainda no segredo dos deuses, só se sabe que será « uma viagem longa e perigosa ». Coloca à disposição de Shandon a fabulosa quantia de dezasseis mil libras para este, de acordo com as pormenorizadas instruções facultadas pelo anónimo remetente da carta, supervisionar a construção de um navio com características especiais que " possa ser lançado ao mar nos primeiros dias de Abril de $1860 \%$. Nesta missiva é igualmente solicitado ao imediato que trate do recrutamento da tripulação adequada para um navio que ainda não existe :

É de toda a conveniência que os homens contratados para fazerem parte da tripulação do Forward sejam ingleses, livres, sem família, solteiros e sóbrios - pois o uso dos espirituosos, e até mesmo da cerveja, não será permitido a bordo -, e que estejam dispostos a tudo ousar e a tudo suportar (Verne, [s.d.] : 22).

Apesar de ser dirigida a subalternos, a exigência que consta da missiva para que os futuros membros da tripulação sejam indivíduos livres, solteiros e sem família é bastante representativa de mais uma marca dos exploradores que os dirigem, em particular, e dos homens de ciência nas Viagens Extraordinárias, a de que uma dedicação exclusiva e radical ao seu ofício científico os obriga a cultivar, tal como os homens de Deus no exercício do seu sacerdócio, uma espécie de celibato e uma casta e pudica abstinência afetiva. Hatteras, tal como o professor Lindenbrock, o capitão Nemo e sobretudo como Robur, a máxima personificação da dimensão autoritária, indomável e absoluta do cientista explorador, submete a si próprio e aos outros uma disciplina de ferro e revela-se, na sua conduta, ilustrando na perfeição os tiques de autoritarismo de muitos homens de ciência oitocentista, um tirano de uma exigência verdadeiramente intratável para os seus acompanhantes, ou não fossem estes obrigados a « tudo ousar e a tudo suportar ». Sendo que, do ponto de vista ficcional, a grande motivação do empreendimento do capitão do Forward que só se interessava pelas descobertas e que sonhava pôr o pé onde nunca ninguém estivesse estado antes, será a da ambição obsessiva de ter a glória de ser o primeiro a atingir o Pólo Norte, é bastante provável que ela tenha sido inspirada num dos maiores mistérios da navegação do século XIX, o episódio verídico do desaparecimento, em 1847, da expedição liderada por Sir John Franklin, composta por dois navios ao serviço do Almirantado britânico, o Erebus e o Terror, que procuravam a descoberta da Passagem do Noroeste.

21 A energia avassaladora, a coragem, o carácter inquebrantável, a determinação irredutível, a força de vontade e a combatividade, traços recorrentes na representação do cientista explorador, estreitamente ligados a uma perseverança e a uma tenacidade que parecem não ter limites por muito difíceis que sejam as privações, não poderiam ter, na figura desta personagem audaciosa dotada de uma fisionomia e de um temperamento a toda a prova, mais distinto depositário.

Neste tempo que é o nosso, mas que começou verdadeiramente a acontecer no século XIX, neste tempo tão indelevelmente marcado pela relevância social e cultural da ciência e da tecnologia, tentar promover a reflexão em torno das importantes questões que envolveram alguns estereótipos do cientista do século XIX a partir da análise da prosa vigorosa e esclarecida de Jules Verne, manifestamente é difícil encontrar produção literária que seja mais adequada ao tema das vicissitudes da edificação da ciência contemporânea, constituiu o humilde desiderato do artigo que agora termina. Esperemos que ele tenha sido moderadamente concretizado. 


\section{BIBLIOGRAFIA}

COTARDIÈre, Philippe de la (dir.) (2005). Júlio Verne : Da Ciência ao Imaginário. Trad. Isabel St. Aubyn. Lisboa : Círculo de Leitores.

DIESBACH, Ghislain (2000). Le tour de Jules Verne en 80 livres. Paris : Perrin.

NOIRAY, Jacques (1998. «Figures du savant », in DUCHET, Claude (ed.). Le Grand Homme, RomantismeRevue du dix-neuvième siècle, n.․ 100, pp. 143-158.

VERNE, Júlio (1978). A Espantosa Aventura da Missão Barsac. Trad. M. Rodrigues Martins. Lisboa : Ed. António Ramos, vol. 2.

(1989). Os Filhos do Capitão Grant. Trad. J. Lima da Costa. Lisboa : edição Livros do Brasil, vol. 1.

(1996). Em Frente da Bandeira. Trad. J. Lima da Costa. Lisboa : Edição Livros do Brasil.

[1971]. Heitor Servadac. Trad. Xavier da Cunha. Amadora : Livraria Bertrand, vol. 2.

(1991). A Ilha Misteriosa. trad. J. Lima da Costa. Lisboa : edição Livros do Brasil, vol. 1.

(2004). Viagem ao centro da Terra. Trad. Mariano de Carvalho. Lisboa : Mediasat Group, SA.

[s.d.]. (Viagens e Aventuras do Capitão Hatteras : O Deserto de Gelo. Trad. Pilar Delvaulx. Lisboa : Publicações Europa-América, vol. 2.

[s.d.]. Viagens e Aventuras do Capitão Hatteras : Os Ingleses no Pólo Norte. Trad. Pilar Delvaulx. Lisboa : Publicações Europa-América, vol. 1.

\section{RESUMOS}

A figura do sábio cientista marca presença significativa em todas as formas de expressão artística e impõe-se como uma das mais paradigmáticas formas de representação da História das ideias e das mentalidades do século XIX. O cientista sábio do século XIX é um produto típico do seu tempo, ele ilustra a síntese perfeita dos valores e das virtudes que enformam a mundividência burguesa. Partindo desta conceção modelar e do princípio de que a ficção literária como modo de inteligibilidade das sociedades humanas pode constituir uma plataforma de grande relevância epistemológica, o presente artigo, tomando como ângulo de abordagem a obra de Jules Verne (1828-1905), essa grande caixa-de-ressonância das antecipações e das conquistas gloriosas mas também dos perigos e das contradições subjacentes ao progresso científico da segunda metade do século XIX, propõe-se fazer uma reflexão sobre os diversos tipos que compõem a figura poliédrica do homem de ciência oitocentista.

The figure of the scientist marks a significant presence in all forms of artistic expression and imposes itself as one of the most paradigmatic forms of representation of the History of ideas and mentalities of the nineteenth century. The scientist of the nineteenth century is a typical product of his time, he illustrates the perfect synthesis of the values and virtues that shape the bourgeois worldview. Starting from this modeling conception and from the principle that literary fiction as a mode of intelligibility of human societies can constitute a platform of great epistemological 
relevance, this paper, taking as an angle of approach the work of Jules Verne (1828-1905), this great box of resonance of the anticipations and the glorious conquests but also of the dangers and contradictions underlying the scientific progress of the second half of the nineteenth century, it is proposed to reflect on the different types that make up the polyhedral figure of the man of science of the nineteenth century.

ÍNDICE

Keywords: science, scientists, literature, Verne (Jules), achievements, dangers

Palavras-chave: ciência, cientistas, literatura, Verne (Jules), conquistas, perigos

\section{AUTOR}

\section{PAULO LAVOURA}

CEIS20 - Universidade de Coimbra

(Grupo de História e Sociologia da Ciência e da Tecnologia)

paulolavoura[at]gmail.com 